\title{
California Workers' Compensation System: Are Occupational Medicine Practice Guidelines Sufficient for the Treatment of Chronic Spinal Pain or Do They Require Supplementation by GUIDELINES FOR INTERVENTIONAL TECHNIQUES?
}

\author{
Standiford Helm II, MD
}

\begin{abstract}
Background: The California Workers' Compensation system mandates the use of occupational medicine practice guidelines developed by the American College of Occupational and Environmental Medicine (ACOEM). These Guidelines cover the treatment of acute (less than three months' duration) injuries. The presence in the ACOEM Guidelines of references to procedures which may be of use after the three-month acute period creates ambiguity as to whether the ACOEM Guidelines are applicable after three months.

ASIPP's “Evidence-Based Practice Guidelines for Interventional Techniques in the Management of Chronic Spinal Pain" are comprehensive, focusing on management of chronic spinal pain.
\end{abstract}

ACOEM guidelines, mandated by the legislature, do not deal explicitly with chronic pain. Their application in managing chronic pain may result in denial of access to appropriate treatment. Thus, ASIPP guidelines may be supplemental to the ACOEM Guidelines. Evaluation of the two Guidelines may clarify which should be followed in the event of ambiguity or conflict.

Methods: The ACOEM and ASIPP Guidelines were evaluated to determine which more closely conformed with accepted standards for guideline creations; which was listed in the Agency for Health Care Research and Quality's (AHRQ) National Guideline Clearinghouse; and what the common references were, how these references were evaluated, how they supported the treatment guidelines offered, and how the ACOEM and ASIPP guidelines differed.
Results: The ASIPP Guidelines complied with 23 out of 25 elements of guideline creation, whereas ACOEM complied with only 12 out of 25 . Only ASIPP is listed in the National Guideline Clearinghouse. ACOEM lists 154 references; ASIPP, 1175; only 20 appear in common. ASIPP's evaluation methodology more closely adhered to the AHRQ methodology. ASIPP's Guidelines are based upon a more robust, detailed analysis.

Conclusion: The ASIPP Guidelines may be considered the applicable Guidelines for the treatment of work-related low back activity limitations persisting beyond three months.

Keywords: Practice guidelines, acute pain, chronic pain, low back pain, activity limitation, work related injuries
The California Workers' Compensation system (1) mandates the use of occupational medicine practice guidelines developed by the American College of Occupational and Environmental Medicine (ACOEM) (2). These guidelines have been created to provide "information and guidance on the generally accepted elements of quality care in occupational and environmental medicine." The guidelines have been created for use by multiple audiences, including "not only healthcare providers, but also insurance professionals, attorneys, and others involved in the

From Pacific Coast Pain Management Center, Lake Forest, California. Address Correspondence: Standiford Helm II, MD, Pacific Coast Pain Management Center, 23792 Rockfield Blvd, Suite 101, Lake Forest, CA 92630 or PO Box 2549, Mission Viejo CA 92690-0549.

E-mail: drhelm@pcpmc.com

Support: Nothing of value received from a commercial entity related to this research

Conflict of Interest: None administration of workers' compensation systems." These guidelines implemented as they are described will hinder patient access following work related injury. The ACOEM guidelines were developed with a narrow focus utilizing only randomized controlled trials with an algorithmic approach for management of low back complaints with a three month time limit.

Clinical practice guidelines are “. . . systematically developed statements to assist practitioner and patient decisions about appropriate healthcare for specific clinical circumstances" (3). There are professional practice recommendations dealing with the prevention, diagnosis and treatment of acute and chronic painful disorders, and in some cases, disability management. Of significant importance are the various guidelines developed by the Agency for Healthcare Policy and Research (AHCPR), which replaced the National Center for Health Services Re- search and Healthcare Technology Assessment (NCHSR) in 1989 (4). The Agency for Healthcare Policy and Research developed approximately 15 guidelines, with a budget of $\$ 750$ million, including the guidelines for managing acute low back pain. However, the Agency for Healthcare Policy and Research has been out of the business of producing guidelines and the guidelines produced by this organization are no longer recommended to be used for patient care.

Among the multiple other guidelines of significance in managing low back pain are "Evidence Based Guidelines for Interventional Techniques in the Management of Chronic Spinal Pain" by American Society of Interventional Pain Physicians (ASIPP) (5). These guidelines are statements developed to improve quality of care, improve patient access, improve patient outcomes, improve appropriateness of care, improve efficiency and effective- 
ness, and achieve cost containment by improving the cost-benefit ratio. In the development of these guidelines, multiple professionals were involved and all types of relevant and published evidence and consensus were utilized.

There a is paucity of literature evaluating the effectiveness or even reasonableness of any type of guideline, even though there has been a rapid increase in guideline developments since 1985 (6). Shaneyfelt et al (7) reviewed the methodological quality of clinical guidelines in the peer-reviewed medical literature, with evaluation of 279 guidelines developed by 69 different organizations and published from 1985 to 1997 . They showed that most guidelines failed to meet the required criteria.

The acceptance by the California Workers' Compensation system of the ACOEM guidelines will impede the improvement of outcomes and appropriateness of care, and may not optimize cost-effectiveness. The extent to which ACOEM guidelines have been accepted by the largest workers' compensation system in the United States is shown by legislation mandating the use of these guidelines, which are considered "presumptively correct on the issue of extent and scope of medical treatment." However, the legislation also states that this presumption is rebuttable and may be controverted by a preponderance of evidence establishing that a variance from the guidelines is reasonably required to cure or relieve the employee. The statute further reads that for injuries not covered by guidelines, "authorized treatment shall be in accordance with other evidence-based medical treatment guidelines generally recognized by the medical community." Thus, this review will focus on a comparison of both guidelines and evaluate the need for supplementation of occupational medicine practice guidelines by ACOEM with "Evidence Based Guidelines for Interventional Techniques in the Management of Chronic Spinal Pain." Thus, the intent of this analysis is to determine whether:

- For injuries not covered by the Guidelines (activity limitations due to symptoms in the low back of greater than three month's duration) whether the ASIPP Guidelines should be considered "evidence based medical guidelines generally recognized by the medical community" which ought to be followed and,
- For injuries or activity limitations which might be interpreted as being covered by the ACOEM Guidelines even if they persist more than three months after the injury (interventions mentioned in the Guidelines which might be applicable after three months), whether the ASIPP guidelines provide "a preponderance of evidence establishing that a variance from the [ACOEM] Guidelines is reasonably required to cure or relieve the employee."

\section{A Critical Analysis}

The American College of Occupational and Environmental Medicine has released the Second Edition of its "Occupational Medicine Practice Guidelines."(2) These guidelines have been created to provide "information and guidance on the generally accepted elements of quality care in occupational and environmental medicine."

The guidelines are divided into two primary sections, one dealing with the "Foundations of Occupational Medicine Practice" and the second with "Presenting Complaints." The "Foundations" section is comprised of six chapters, dealing with Prevention, Initial Assessment and Documentation, Initial Treatment, Work Relatedness, Disability Prevention and Management, Pain, Suffering, and the Restoration of Function and Independent Medical Examinations. The "Presenting Complaints" section deals with the evaluation and treatment of nine different body areas. From the perspective of an Interventional Pain Management physician, the most relevant chapter is Low Back Complaints.

Each of the nine chapters dealing with specific regions of the body is divided into a General Approach and Basic Principles section, with an emphasis on the initial assessment with the history and physical exam. Treatment options, including surgical considerations, are dis-

Table 1. ACOEM designation of levels of strength of medical evidence
\begin{tabular}{|c|l|}
\hline Level A & $\begin{array}{l}\text { Strong research-based evidence provided by generally consistent findings and } \\
\text { multiple (more than one) high-quality randomized controlled trials (RCTs) }\end{array}$ \\
\hline Level B & $\begin{array}{l}\text { Moderate research-based evidence provided by generally consistent findings } \\
\text { and one high-quality RCT and one or more low-quality RCTs, or generally } \\
\text { consistent findings and multiple low quality RCTs }\end{array}$ \\
\hline Level C & $\begin{array}{l}\text { Limited research based evidence provided by one RCT (either high-or low- } \\
\text { quality) or inconsistent or contradictory evidence findings in multiple RCTs }\end{array}$ \\
\hline Level D & No research-based evidence, no RCTs \\
\hline
\end{tabular}

cussed. In the instance of low back pain, the surgical considerations discussed include lumbosacral nerve root decompression, intradiscal electrothermal annuloplasty (IDET), spinal cord stimulation, the management of spinal stenosis and spinal fusion. There is finally a summary of evidence and recommendations.

The ACOEM goes to considerable effort to discuss the methodology as to how they developed these guidelines. Each chapter represents an updating of the original Guidelines, published in 1997. Medical library research services were contracted out to the Work Lost Data Institute, which generated the corpus of literature to be evaluated in the review. Underlining the desire to create an evidencebased guideline, the Guidelines contain an Appendix discussing in considerable depth the process by which literature is evaluated. Included here is a discussion of study design, statistical analysis and the analysis and application of study results. In analyzing the study results, a system of stratifying evidence for a procedure by strength was adopted from the Agency for Health Care Research and Quality (AHRQ) and the Cochrane Review. This system is presented in Table 1, "ACOEM Designation of Levels of Strength of Medical Evidence."

It is of interest that, in contrast to principles of evidence-based medicine $(6,8)$, the schema used by ACOEM focuses solely on randomized controlled trials (RCTs), with no mentioned inclusion of other data sources, such as systematic reviews, observational studies and diagnostic test studies.

The ACOEM strove to have a wide base of varying medical specialties in creating these Guidelines, with the input of "virtually all specialties involved in occupational medicine" in order to represent the "current, collective voice of healthcare professionals across the spectrum of specialists who treat work-related injuries and occupational diseases." The goal 
Table 2. ASIPP designation of levels of strength of medical evidence

\begin{tabular}{|c|l|}
\hline Level I & $\begin{array}{l}\text { Conclusive: Research-based evidence with multiple relevant and high-quality } \\
\text { studies or consistent reviews of meta-analysis }\end{array}$ \\
\hline Level II & $\begin{array}{l}\text { Strong: Research-based evidence from at least one properly designed } \\
\text { randomized, controlled trial of appropriate size (with at least 6o patients } \\
\text { in the smallest group); or research-based evidence from multiple properly } \\
\text { designed studies of smaller size; or at least one randomized controlled trial, } \\
\text { supplemented by supplemented by predominantly positive prospective and/ } \\
\text { or retrospective evidence }\end{array}$ \\
\hline Level III & $\begin{array}{l}\text { Moderate: Evidence from a well-designed small randomized trial or evidence } \\
\text { from well-designed trials without randomization, or quasi-randomized studies, } \\
\text { single group, pre-post cohort, time series, or matched case-controlled studies } \\
\text { or positive evidence from at least one meta-analysis }\end{array}$ \\
\hline Level IV & $\begin{array}{l}\text { Limited: Evidence from well-designed nonexperimental studies from more } \\
\text { than one center or research group }\end{array}$ \\
\hline Level V & $\begin{array}{l}\text { Indeterminate: Opinions from respective authorities, based upon clinical } \\
\text { evidence, descriptive studies, or reports of expert committees }\end{array}$ \\
\hline
\end{tabular}

of the Guidelines is "to improve the efficiency [of diagnosis].... and the effectiveness of...treatment in relieving symptoms and achieving cure."

Chapter 12, Low Back Complaints, of the Guidelines, focuses on acute low back pain: "Recommendations on assessing and treating adults with... low back problems (i.e. activity limitations due to symptoms in the low back of less than three months (sic) duration) are presented in this clinical practice guidelines." This three-month time limit is reinforced by the treatment algorithms presented in the chapter, which clearly limit their assessment to workers with lowback-related activity limitation of less than three month's duration. Accordingly, these Guidelines, when viewed specifically for the treatment of low back pain, are meant to be utilized solely for patients with acute (less than three months' duration) low back pain.

ASIPP has published a similar review of the literature, with resulting treatment guidelines, entitled "Evidence-Based Practice Guidelines for Interventional Techniques in the Management of Chronic Spinal Pain"(5), focusing solely upon the use interventional techniques in treating chronic spinal pain. The definition of chronic is elusive, but that offered by Bonica is widely accepted:

Chronic pain is "pain which persists a month beyond the usual course of acute disease or a reasonable time for any injury to heal itself that is associated with chronic pathological processes that cause a continuous pain or pain at intervals for months or years"(5).
The ASIPP guidelines are accompanied by a companion article discussing, in a manner analogous to the Appendix of the ACOEM Guidelines, the theory and process of reviewing literature in the course of developing evidence-based practice guidelines (6). This article describes in considerable detail the extent to which many systematic reviews in interventional pain management fail to follow evidencebased medicine principles. Of interest in this article is the discussion in detail of the AHRQ methodology for evaluating the medical literature, including the support given by the AHRQ to observational studies in addition to randomized clinical trials. By recognizing the value of studies other than RCTs, the AHRQ opens the door to a much richer, more robust source of data, including systematic reviews, nonrandomized and observational studies and case series. The AHRQ support of studies other than randomized clinical trials is important because of the multiple difficulties in performing randomized clinical trials to evaluate procedures and interventions. RCTs are associated with multiple problems, including difficulties with achieving true randomization, ethprocedures and the difficulty in recruiting a sufficiently large database to generate powerful statistical analysis. Note, for example, the problems faced by Pauza et al (9), in a Volvo Award winning randomized, prospective, placebo-controlled study of the IDET procedure, in which 1,360 patients had to be evaluated in order to enter 64 patients into the study after discography (9).

The ASIPP Guidelines utilize the ical considerations of performing sham
AHRQ methodology to assess the quality of the literature supporting an intervention. This information is presented in a slightly different format than that used by the ACOEM. This format provides somewhat more clarity as to the distinction between the various levels of evidence and clearly emphasis the contribution of multiple types of studies, as shown in Table 2, "ASIPP designation of levels of strength of medical evidence."

It appears at first glance that there is a clear-cut distinction between the ACOEM and ASIPP Guidelines, with a clear transition from one to the other at three months. In practice, the distinction is not so crystalline, with reference in the ACOEM guidelines to procedures, such as epidural or facet injections, which might have benefit after three months, and procedures such as nucleoplasty or intradiscal electrothermal therapy (IDET), which would rarely be used within the first three months. Given the importance of the ACOEM Guidelines because of the legislative mandate for their use, it is helpful to compare the ACOEM and ASIPP Guidelines to determine which should be considered applicable when the injury or work limitation has persisted after three months.

The comparison of two guidelines can be problematic. Multiple guidelines have been developed by numerous groups, including government agencies, general and subspecialty medical societies, insurers and private organizations. The existence of guidelines generates a great debate, including concerns of "cookbook" medicine. Different guidelines can produce, depending upon the intellectual foundations of the authors, widely differing analyses of the same or similar data (8). At best, guidelines can assist:

- $\quad$ Patients in making informed health care decisions,

- Physicians in using appropriate technology and avoiding inappropriate care, and

- Insurers in authorization and reimbursement decisions.

A validated methodology was published in the Journal of the American Medical Association by Shaneyfelt, et al (7), which brings some order to the question as to whether differing guidelines have been developed with equal attention to the underlying principles of guideline creation. This approach, along with 
a close contextual analysis, can be used to compare the two Guidelines. Amongst the questions to be answered in a contextual analysis are:

- Whether the same data was analyzed,

- Whether there is consistency in their conclusions,

- If there is an inconsistency, what the basis of that inconsistency might be, and,

- If there is an inconsistency, to resolve which data analysis provides more powerful conclusions for directing patient care.

The AHRQ maintains, along with the American Medical Association and the American Association of Health Plans-Health Insurance Association of American, a National Guideline Clearinghouse (NGC) to provide interested users access to clinical practice guidelines. The NGC has straightforward, relatively easily achieved criteria for inclusion:

1. The Guideline must have systematically developed statements that include recommendations, strategies, or information that assist health care practitioners and patients make decisions about appropriate health care for specific clinical circumstances.

2. The clinical practice guideline must be produced under the auspices of an organization, such as a medical specialty society or a government agency.

3. Documentation that a systematic literature search and review of existing scientific evidence occurred must be producible.

4. The guideline must be current and in English.

Inclusion in the NGC provides a loose mantle of authenticity. This mantle is not exclusive, either in terms of the rigor required to gain it or in terms of denigrating all guidelines which do not have this mantle. It does imply a commitment on the part of the creators of the included guidelines because of their willingness to submit them for evaluation.

\section{Methods}

The ACOEM and ASIPP Guidelines were assessed according to the twentyfive criteria listed by Shaneyfelt et al (7). Simple summing of the number of criteria, which were met, gives relative weightings as to how closely the Guidelines ad- hered to the key elements in developing Guidelines.

The two Guidelines were also evaluated as to whether they were listed in the National Guideline Clearinghouse (NGS). This was done by a site search at the NGS website at www.guideline.gov.

In addition, the references contained in Chapter 12, "Low Back Complaints" of the ACOEM Guidelines were compared with the references listed in the ASIPP Guidelines. References included in both

Guidelines were then evaluated as to how to each Guideline assessed the reference and applied it to the intervention being examined. In addition, each Guideline was evaluated to determine whether it had accessed the complete corpus of studies relevant to the question at hand, with appropriate search strategy.

Finally, the treatment recommendations, limited solely to interventional pain techniques for each Guideline, were contrasted.

Table 3. Comparison of the ACOEM and ASIPP Guidelines according to how closely they follow the key elements in guideline development

\begin{tabular}{|c|c|c|}
\hline $\begin{array}{c}\text { Key } \\
\text { Element }\end{array}$ & $\begin{array}{c}\text { ACOEM } \\
\text { Adherence }\end{array}$ & $\begin{array}{c}\text { ASIPP } \\
\text { Adherence }\end{array}$ \\
\hline \multicolumn{3}{|l|}{ STANDARDS ON GUIDELINES DEVELOPMENT AND FORMAT } \\
\hline Purpose of the guideline is specified & Yes & Yes \\
\hline Rationale and importance of the guideline is explained & Yes & Yes \\
\hline The participants and their area of expertise are specified & Yes & Yes \\
\hline Targeted health problem is clearly defined & Yes & Yes \\
\hline Targeted patient population is specified & Yes & Yes \\
\hline Intended audience of users is specified & Yes & Yes \\
\hline $\begin{array}{l}\text { The principal preventive, diagnostic or therapeutic options } \\
\text { available to clinicians and patients are specified }\end{array}$ & Yes & Yes \\
\hline The health outcomes are specified & Yes & Yes \\
\hline $\begin{array}{l}\text { The method by which the guideline underwent external review } \\
\text { is specified }\end{array}$ & No & No \\
\hline An expiration date or date of scheduled review is specified & No & Yes \\
\hline \multicolumn{3}{|l|}{ STANDARDS ON EVIDENCE IDENTIFICATION AND SUMMARY } \\
\hline Method of identifying scientific evidence is specified & No & Yes \\
\hline Time period from which evidence is reviewed is specified & No & No \\
\hline Method for grading or classifying the evidence is specified & Yes & Yes \\
\hline Method of data extraction is specified & No & Yes \\
\hline $\begin{array}{l}\text { Method for grading or classifying the scientific evidence is } \\
\text { specified }\end{array}$ & Yes & Yes \\
\hline $\begin{array}{l}\text { Formal methods of combining evidence or expert opinion are } \\
\text { used and described }\end{array}$ & No & Yes \\
\hline Benefits and harms of specific health practices are specified & No & Yes \\
\hline Benefits and harms are quantified & No & Yes \\
\hline $\begin{array}{l}\text { The effect on health care costs from specific health practices } \\
\text { is specified }\end{array}$ & No & Yes \\
\hline Costs are quantified & No & Yes \\
\hline \multicolumn{3}{|l|}{ STANDARDS ON THE FORMULATION OF RECOMMENDATIONS } \\
\hline The role of value judgments used is discussed & No & Yes \\
\hline The role of patient preference is discussed & No & Yes \\
\hline $\begin{array}{l}\text { Recommendations are specific and apply to the stated goals } \\
\text { of the guideline }\end{array}$ & Yes & Yes \\
\hline $\begin{array}{l}\text { Recommendations are graded according to the strength of the } \\
\text { evidence }\end{array}$ & Yes & Yes \\
\hline Flexibility in the recommendations is specified & No & Yes \\
\hline TOTAL “YES” Responses & 12 & 23 \\
\hline
\end{tabular}




\section{RESULTS}

The results of comparing the two studies according the methodology presented in JAMA (7) are presented in Table 3, "Comparison of the ACOEM and ASIPP Guidelines according to how closely they follow the key elements in guideline development."

The ACOEM Guidelines conform to 12 of the 25 key elements. There are shortcomings in clarifying how the doc- ument underwent external review, when the next review is scheduled, how the data were identified, what time period the reviewed evidence covered, how the data were extracted, how evidence and expert opinion were combined, what the benefits and harms of specific procedures are, whether these benefits and harms were quantified, what the effect on health care costs are and whether costs are quantified, what the role of value judgments and patient preferences are, and whether there is flexibility in application of the guidelines. The ASIPP Guidelines conform to 23 of the key elements, with no mention of the time period the reviewed evidence covered and no discussion of external review.

With regards to listing in the $\mathrm{Na}$ tional Guideline Clearinghouse, only the ASIPP document is listed in the Clearinghouse. While the ACOEM Guidelines appear to meet the inclusion criteria, ACOEM is not currently listed in the NGC.

Table 4. Comparison of the critical evaluation in the ACOEM and ASIPP guidelines for those studies used in both guidelines

\begin{tabular}{|c|c|c|}
\hline Author & ACOEM Commentary & ASIPP Commentary \\
\hline $\begin{array}{l}\text { Kang et al } \\
(11)\end{array}$ & $\begin{array}{l}\text { No specific reference. Note that this } \\
\text { reference appears twice. }\end{array}$ & $\begin{array}{l}\text { One of } 15 \text { studies showing that "a multitude of other inflammatory agents... } \\
\text { play a role in the inflammatory process." }\end{array}$ \\
\hline $\begin{array}{l}\text { Saal \& Saal } \\
(12,13)\end{array}$ & $\begin{array}{l}\text { None specifically identified. Support for } \\
\text { IDET equivocal. Pauza et al's study is not } \\
\text { referenced. }\end{array}$ & $\begin{array}{l}\text { Two of seven studies evaluating IDET, including Pauza et al 's randomized } \\
\text { trial. }\end{array}$ \\
\hline $\begin{array}{l}\text { Carette et al } \\
(14)\end{array}$ & No specific reference & $\begin{array}{l}\text { One of ten randomized trials of interlaminar epidural injections, discussing } \\
\text { participants, interventions, outcomes, results and conclusion. }\end{array}$ \\
\hline $\begin{array}{l}\text { Hopwood \& } \\
\text { Abram (15) }\end{array}$ & No specific reference & $\begin{array}{l}\text { One of } 48 \text { studies of varying quality evaluating interlaminar epidural } \\
\text { injections. }\end{array}$ \\
\hline $\begin{array}{l}\text { Bowman et } \\
\text { al (16) }\end{array}$ & No specific reference & $\begin{array}{l}\text { One of } 48 \text { studies of varying quality evaluating interlaminar epidural } \\
\text { injections. This specific reference appears to have been inadvertently not } \\
\text { included in the range of studies cited. }\end{array}$ \\
\hline $\begin{array}{l}\text { Nelemans et } \\
\text { al (17) }\end{array}$ & No specific reference & $\begin{array}{l}\text { Caudal and interlaminar epidurals } \\
\text { were not analyzed separately. }\end{array}$ \\
\hline $\begin{array}{l}\text { Van Tulder et } \\
\text { al (18) }\end{array}$ & No specific reference & $\begin{array}{l}\text { Caudal and interlaminar epidurals } \\
\text { were not analyzed separately. }\end{array}$ \\
\hline $\begin{array}{l}\text { Rozenberg et } \\
\text { al (19) }\end{array}$ & No specific reference & $\begin{array}{l}\text { One of } 14 \text { systemic reviews of epidural steroid injections. The shortcomings of } \\
\text { this, and other, systemic reviews are noted. }\end{array}$ \\
\hline $\begin{array}{l}\text { Indahl at al } \\
(20)\end{array}$ & No specific reference & $\begin{array}{l}\text { One of five papers reporting low levels of chronicity. ASIPP document also } \\
\text { mentions } 10 \text { papers, not mentioned in ACOEM, suggesting higher levels of } \\
\text { chronicity. }\end{array}$ \\
\hline $\begin{array}{l}\text { Carragee et } \\
\text { al (20-24) }\end{array}$ & $\begin{array}{l}\text { Discography is not well supported by the } \\
\text { medical evidence (22). }\end{array}$ & Four of 42 studies on discography. Criticized on methodological grounds \\
\hline $\begin{array}{l}\text { Lee et al } \\
(25)\end{array}$ & No specific reference & $\begin{array}{l}\text { One of four articles showing negative results of discogram. Eleven additional } \\
\text { studies showing positive results from discograms are also referenced. }\end{array}$ \\
\hline $\begin{array}{l}\text { Bigos et al } \\
(10)\end{array}$ & $\begin{array}{l}\text { Its } 373 \text { references are specifically incor- } \\
\text { porated into the Guidelines. This docu- } \\
\text { ment does not reflect current clinical } \\
\text { practice. }\end{array}$ & $\begin{array}{l}\text { One of } 49 \text { studies documenting "a wide degree of variance in the definition } \\
\text { and the practice of interventional pain management." }\end{array}$ \\
\hline $\begin{array}{l}\text { Dreyfuss et } \\
\text { al }(26)\end{array}$ & No specific reference & $\begin{array}{l}\text { One of four prospective and three retrospective studies of facet denervation. } \\
\text { This is a nonrandomized study. }\end{array}$ \\
\hline $\begin{array}{l}\text { Van Kleef et } \\
\text { al (27) }\end{array}$ & No specific reference & $\begin{array}{l}\text { One of four prospective and three retrospective studies of facet denervation. } \\
\text { This is a randomized study. }\end{array}$ \\
\hline $\begin{array}{l}\text { Leclaire et al } \\
(28)\end{array}$ & No specific reference & $\begin{array}{l}\text { This study had been excluded from an analysis of facet joint neurotomy } \\
\text { for failure to provide specific inclusion and exclusion criteria as well as } \\
\text { appropriate diagnostic evaluation. }\end{array}$ \\
\hline $\begin{array}{l}\text { Franklin et al } \\
(29)\end{array}$ & No specific reference & One of 27 references on the incidence of post laminectomy syndrome. \\
\hline
\end{tabular}




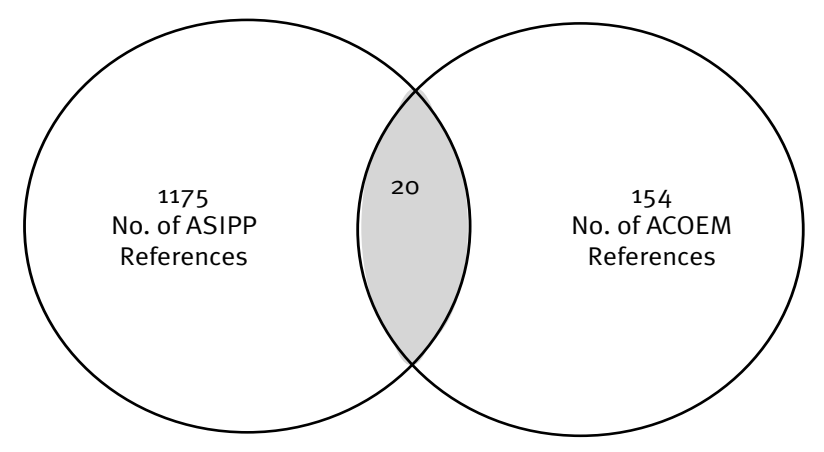

Fig. 1. Venn Diagram demonstrating 20 common references between the two guidelines

The ASIPP study includes 1175 ref- includes 154 references. In addition, erences. Chapter 12 of the ACOEM study Chapter 12 incorporates by notation an additional 373 references cited in a 1994 Agency for Health Care Policy and Research Publication, Acute Low Back Problems in Adults (10). These additional 373 references were not incorporated in the current study because they deal specifically with the acute treatment of low back pain, whereas the focus of this analysis is on the treatment of chronic back pain, and because the preponderance of the seminal work in the interventional treatment of low back pain has occurred since 1994. Further, when one obtains a copy of this document, it comes with a cover sheet stating "[The AHCPR publication] is no longer viewed as guidance for current medical practice."

As both references deal with back

Table 5. Comparison of the strength of evidence analyses made by ACOEM and ASIPP

\begin{tabular}{|c|c|c|}
\hline Procedure & ACOEM & ASIPP \\
\hline \multicolumn{3}{|c|}{$\begin{array}{l}\text { Diagnostic Injections } \\
\text { (Evaluate validity, specificity and sensitivity } \\
\text { of the injections) }\end{array}$} \\
\hline Facet Joint Injections & Not recommended & Strong \\
\hline Provocative Lumbar Discography & Not recommended & $\begin{array}{l}\text { Strong, if supported by } \mathrm{H} \& \mathrm{P} \text { and imaging } \\
\text { studies }\end{array}$ \\
\hline Transforaminal ESI & Not recommended* & $\begin{array}{l}\text { Moderate if nerve root irritation; limited if no } \\
\text { nerve root irritation }\end{array}$ \\
\hline Sacroiliac Joint Injections & Not discussed & Moderate \\
\hline \multicolumn{3}{|l|}{ Therapeutic Interventions } \\
\hline Facet injections: intraarticular & Not recommended ${ }^{\star \star}$ & $\begin{array}{l}\text { Short-term relief: moderate } \\
\text { Long-term relief: limited }\end{array}$ \\
\hline Facet injections: medial branch & Not recommended & $\begin{array}{l}\text { Short-term relief: strong } \\
\text { Long-term relief: moderate }\end{array}$ \\
\hline Facet: medial branch neurotomy & Not recommend & $\begin{array}{l}\text { Short term relief: strong } \\
\text { Long-term relief: moderate }\end{array}$ \\
\hline Epidural injections: caudal & $\begin{array}{l}\text { Optional (C) if nerve root irritation } \\
\text { Not Recommended }(\text { D) if no nerve root } \\
\text { irritation }\end{array}$ & $\begin{array}{l}\text { Short-term relief: strong } \\
\text { Long-term relief: moderate }\end{array}$ \\
\hline Epidural injections: interlaminar & $\begin{array}{l}\text { Optional (C) if nerve root irritation } \\
\text { Not Recommended } \quad \text { (D) if no nerve root } \\
\text { irritation }\end{array}$ & $\begin{array}{l}\text { Short-term relief: moderate } \\
\text { Long-term relief: limited }\end{array}$ \\
\hline Epidural injections: transforaminal & $\begin{array}{l}\text { Optional (C) if nerve root irritation } \\
\text { Not Recommended } \quad \text { (D) if no nerve root } \\
\text { irritation }\end{array}$ & $\begin{array}{l}\text { Short-term relief: strong } \\
\text { Long-term relief: strong }\end{array}$ \\
\hline Epidural adhesiolysis & Not evaluated & $\begin{array}{l}\text { Short-term relief: moderate } \\
\text { Long-term relief: moderate }\end{array}$ \\
\hline IDET & Discussed, not formally rated. & $\begin{array}{l}\text { Short-term relief: moderate } \\
\text { Long-term relief: limited }\end{array}$ \\
\hline Nucleoplasty & Optional: Chymopapain & Limited \\
\hline Spinal Cord Stimulation & Reserved for select patients & Long-term relief: moderate \\
\hline Intrathecal infusion systems & Not discussed. & Long-term relief: moderate \\
\hline
\end{tabular}

* ACOEM does not distinguish between the caudal, interlaminar and transforaminal approaches for epidurals

** ACOEM does not distinguish between intra-articular diagnostic injections, medial branch diagnostic injections, intra-articular therapeutic injections, medial branch therapeutic injections or medial branch neurotomy

See Tables 1 and 2 for definitions of levels of strength for medical evidence. 
pain, it is reasonable to examine whether they covered the same database. A review of the references indicates that the two studies shared 20 references. The limited extent of this overlap is shown in Figure 1, "Venn diagram demonstrating 20 common references between the two Guidelines."

How each guideline respectively commented on each of the studies common to both guidelines is shown in Table 4 , "Comparison of the critical evaluation in the ACOEM and ASIPP guidelines for those studies used in both Guidelines."

Table 5, "Comparison of the strength of evidence analyses made by ACOEM and ASIPP" presents the comparison of the analysis made by ACOEM and ASIPP respectively as to the strength of evidence supporting a given intervention.

\section{DISCUSSION}

The ASIPP guidelines applied the preponderance of key elements, as identified in the JAMA study, in guideline creation, conforming to 23 out of 25 elements. The ACOEM guidelines, on the other hand, conformed to only 12 of 25 elements and fall short in several categories of the standards necessary for satisfactory guideline development. They do not formally describe how they combine scientific evidence or expert opinion. The method by which they obtained their evidence is not clear and there is no notation as to what evidence applies to what clinical intervention. Costs are not mentioned. There is neither mention of patient values nor of the values of the developers of the guidelines. Given the extent to which conclusions are driven by perspective, a discussion of the preferences and opinions of the developers is necessary for intellectual clarity.

The National Guideline Clearinghouse is an AHRQ-sponsored and maintained website that attempts to gather all guidelines meeting appropriate criteria in one spot for easy review and dissemination. While an absence from the NGC says nothing about quality of excluded guidelines, inclusion does suggest a willingness on the part of the authors to have at least the summary data of their guidelines widely and freely disseminated. Only the ASIPP Guidelines are included on National Guidelines Clearinghouse. While the ACOEM Guidelines appear to qualify for inclusion, they are not currently listed on the NGC.
In examining whether the same data set was evaluated, only a very small minority of studies, 20 out of 1175 ASIPP references and 154 ACOEM references, were used in both guidelines. It is reasonable to expect multiple references appearing in the ACOEM guidelines to not appear in the ASIPP guidelines because the ACOEM guidelines are dealing with all aspects of low back pain, where as ASIPP guidelines are dealing only with interventional pain management techniques. However, the converse is not true, in that, as interventional pain management procedures are a subset of the treatment of low back pain, the data evaluated by ASIPP could reasonably be considered an appropriate corpus of data for analysis by ACOEM.

A possible explanation to the limited review by ACOEM of the literature evaluated by ASIPP is that ACOEM did not evaluate literature relating to pain lasting more than three months.

Another reason for this difference in the number of reviewed articles is the differing view as to what constitutes a valid data source. Both Guidelines reference the AHRQ methodology, but appear to interpret it quite differently. The ACOEM schema for evaluating a procedure or intervention is limited to randomized, controlled trials. The ASIPP interpretation, drawn more closely from, and with what appears to be a better understanding of the spirit and intent of, the AHRQ approach, allows all relevant data sources to be incorporated. The interpretation allows for a more robust analysis.

ASIPP also provides critical analysis of the specific papers, using a clearly delineated approach defining which data elements need to be present in any given source. This critique offers guideposts by which the literature can be evaluated, allowing the elimination of studies which fail to meet methodological guidelines. ACOEM provides no such critical analysis and appears to accept its referenced studies at face value, with no easily obtainable analysis as to how well a study was designed or implemented.

A further difficulty with analyzing the ACOEM Guidelines is the general failure to footnote specific conclusions to specific references. One is left to infer which references are utilized to support any given position, creating the need for exegesis in a document whose ostensible purpose is to bring clarity.

The apparent lack of breadth and in- clusion in the data reviewed by the ACOEM is highlighted by the review of the common references. Kang et al (11) is one of fifteen studies dealing not with the importance of inflammatory agents in radicular pain, but merely the miscellaneous inflammatory agents which can be found. Saal and Saal $(12,13)$ are two of seven articles on IDET. Included in the ASIPP study, which was published before the ACOEM Guidelines, is reference to the Volvo Award winning prospective evaluation of the IDET procedure by Pauza et al (9). ASIPP, because its search and inclusion methodology was more far reaching, was able to include Pauza's work on the basis of a prepublication presentation.

Carette et al's (12) New England Journal of Medicine article demonstrating the lack of efficacy of interlaminar epidural steroid injections is one of ten randomized trials on that topic. Hopwood and Abram (15) and Bowman et al (16) are two of forty-eight nonrandomized studies on interlaminar epidurals.

Reviews of Nelemans et al (17) and van Tulder et al (18) were both found deficient by the ASIPP study in that they did not distinguish between the interlaminar and caudal approaches and failed to include transforaminal epidurals. By lumping together a procedure which is not efficacious with one which is, they lose the ability to pick out the approach which does offer benefit.

Rozenberg et al (19) is one of 14 systemic reviews of epidural steroid injections. The shortcomings of this, and other, systemic reviews are noted in the ASIPP document; the ACOEM appears to accept it uncritically.

Indahl et al (20) were offered as documentation that the incidence of chronicity of low back pain is low. In the ASIPP work, Indahl et al's (20) reference is one of five manuscripts presenting that position. Absent in the ACOEM references are 10 studies suggesting a considerably higher level of chronicity of low back pain.

Carragee et al (21-24) and Lee et al (25) provide 5 of over 50 studies on discography. Carragee et al (21-24), in particular, have generated considerable debate on his methodology. In examining all of the evidence, the ASIPP Guidelines conclude that discography is warranted if utilized in the context of the appropriate history and imaging studies. This conclusion, based on a critical analysis of a wide array of evidence, is diametrically 
opposed to that of the ACOEM. In addition, ACOEM denigrates IDET specifically because the decision to perform the IDET procedure is based upon the results of discography.

Dreyfuss et al (26) and van Kleef et al (27) provided evidence on the efficacy of radiofrequency in chronic low back pain. In the ASIPP Guidelines, they stand as two of seven articles on this topic. In the absence of any specific comments in the ACOEM guidelines regarding radiofrequency, it is not possible to know how the ACOEM has evaluated these two studies. Regardless, ASIPP has examined a broader database more critically. An example of this is ACOEM's troubling reference to Leclaire et al's study (28). Presumably, the study is included as a supportive reference. However, it had been excluded from the ASIPP analysis of facet joint neurotomy for failure to provide specific inclusion and exclusion criteria as well as appropriate diagnostic evaluation. Its inclusion highlights the apparent lack of critical analysis of the supporting documents.

Inclusion of a study by Franklin et al (29) on post laminectomy syndrome is another example of using a small selection of the available literature. It is one of 27 articles on this subject referenced in the ASIPP's evidence-based guidelines.

The comparison of the treatment suggestions is also interesting. The ASIPP guidelines create several important distinctions, not provided in the ACOEM guidelines. Specifically, the ASIPP guidelines note important distinctions

- Between diagnostic and therapeutic injections,

- Between different approaches to the same procedure, such as interlaminar versus caudal versus transforaminal steroid injections, and

- Between therapeutic procedures using local anesthetics and those using ablative procedures, such as radiofrequency thermocoagulation.

The two guidelines also come to starkly different, occasionally diametrically opposed, conclusions as to the efficacy of various procedures. For example, in the ACOEM Guidelines, all facet injections are not recommended. In the ASIPP Guidelines, diagnostic facet joint injections are supported by strong evidence. Therapeutic facet joint injections are supported by anywhere from strong to limited evidence, depending upon wheth- er relief is short-term or long-term and whether the technique is an intra-articular injection, a medial branch injection or a neurotomy.

The handling of the applicability of epidural steroid injections is similarly disparate. The ACOEM Guidelines consider them "optional" in the presence of radicular findings and not recommended if there is no evidence of nerve root irritation. These statements need to be further clarified in light of the information provided in the ASIPP Guidelines. The ASIPP study shows that the approach defines the efficacy: transforaminal and caudal injections are better supported by the literature than are interlaminar injections. To ignore this distinction and view interlaminar injections as on a par with the other approaches does not appear to be supported by the literature.

The ACOEM Guidelines also fail to mention several procedures whose efficacy is justified by the literature. These are diagnostic sacroiliac joint injections, percutaneous lysis of epidural adhesions with hypertonic saline and the use of implantable, programmable pumps for the intrathecal placement of medications such as opioids and local anesthetics. All of these procedures do warrant, based on a critical examination of the literature, a place in the treatment algorithm.

The ACOEM handling of nucleoplasty is confusing, in that chymopapain is considered optional. This recommendation has limited value to the injured worker in the United States, as chymopapain is not available to physicians in the United States. Numerous other technologies are also available to perform nucleoplasties, but none are referenced in the ACOEM literature. ASIPP guidelines note that the current literature provides only limited support for this procedure.

IDET is a controversial procedure which has generated much discussion. ASIPP finds that the evidence for shortterm relief is moderate. ACOEM does not offer a clear-cut stand. They appear to avoid the issue by attempting to declare it moot, as the decision to perform IDETs is based upon the results of discography, a technology which ACOEM (but not ASIPP) discredits.

The analysis provided by ASIPP as to the strength of evidence supporting various interventions has been refined into two proposed low back treatment algorithms (5). These algorithms are more fully discussed in a previous ASIPP Guideline (30). Figure 2 presents an algorithmic approach to the application of therapeutic interventional techniques in the management of chronic low back pain. Figure 3 presents an algorithmic approach to the treatment of chronic low back pain without disc herniation (somatic or nonradicular pain).

In addition to the proposed algorithmic approaches, the ASIPP Guidelines offer detailed commentary as to what criteria should be considered prior to performing any intervention and, for selected procedures, how often various interventions should be delivered and what thresholds should be met to warrant repeating procedures.

The ASIPP Guidelines have provided a robust, incisive, encyclopedic analysis of the available medical evidence pertaining to the use of interventional techniques in treating low back injuries which limit activity for more than three months after the injury. They comply more closely with the accepted criteria for guideline development than do the ACOEM Guidelines. The ASIPP Guidelines cover injuries not covered by the ACOEM Guidelines and are clearly "evidence based medical guidelines generally recognized by the medical community". There should be no confusion as to whether the ACOEM Guidelines cover injuries after three months, given the clear description of the ACOEM methodology and intent; they do not apply to chronic low back pain. Accordingly, the ASIPP Guidelines should be considered as a supplement to the ACOEM Guidelines, dealing with low back related activity limitations persisting beyond three months.

\section{CONCLUSION}

ACOEM has published its second edition of Occupational Medicine Practice Guidelines. These Guidelines offer a well considered and valuable means to evaluate and treat acute occupational medical problems. The ACOEM Guidelines provide a comprehensive, well-considered methodology for dealing with acute low back activity limitations. They are not designed to deal with chronic low back related activity limitations.

They have been mandated in California as being the appropriate Guidelines to follow for work related injuries. California law allows other generally accepted evidence-based Guidelines to supplement 


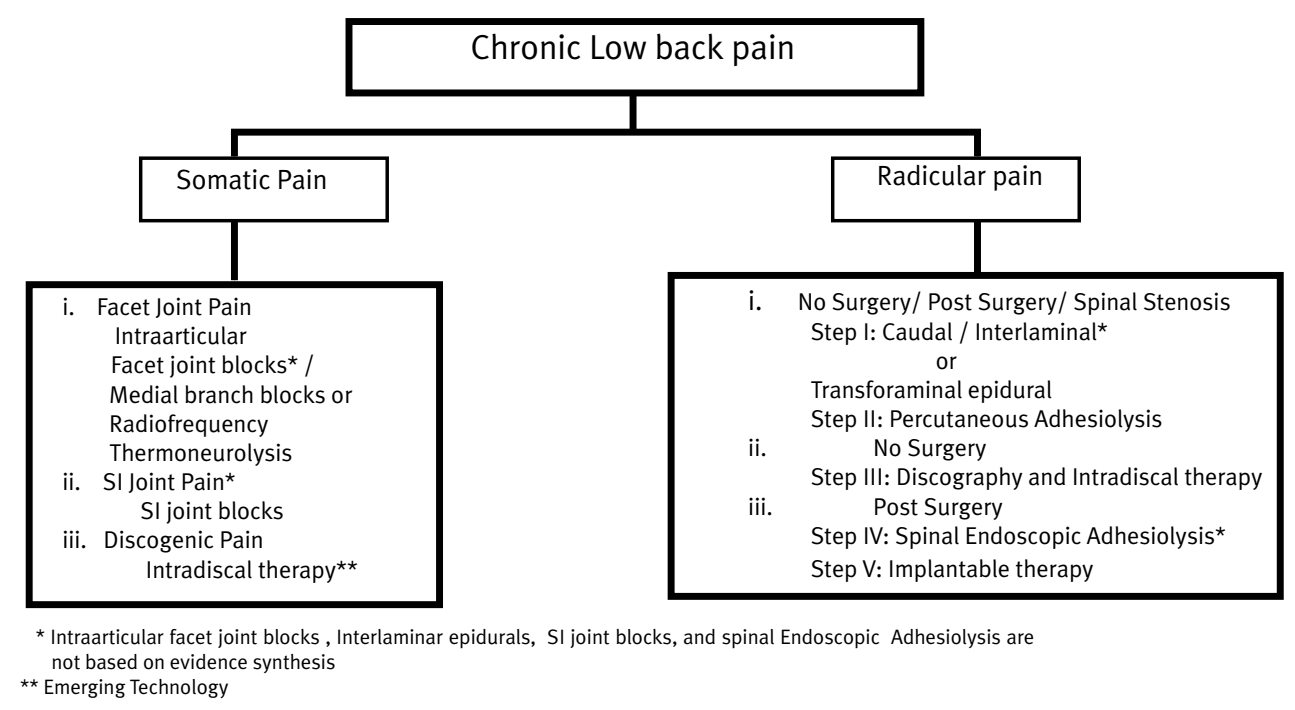

Fig. 2 An algorithmic approach to the application of therapeutic interventional techniques in the management of chronic low back pain

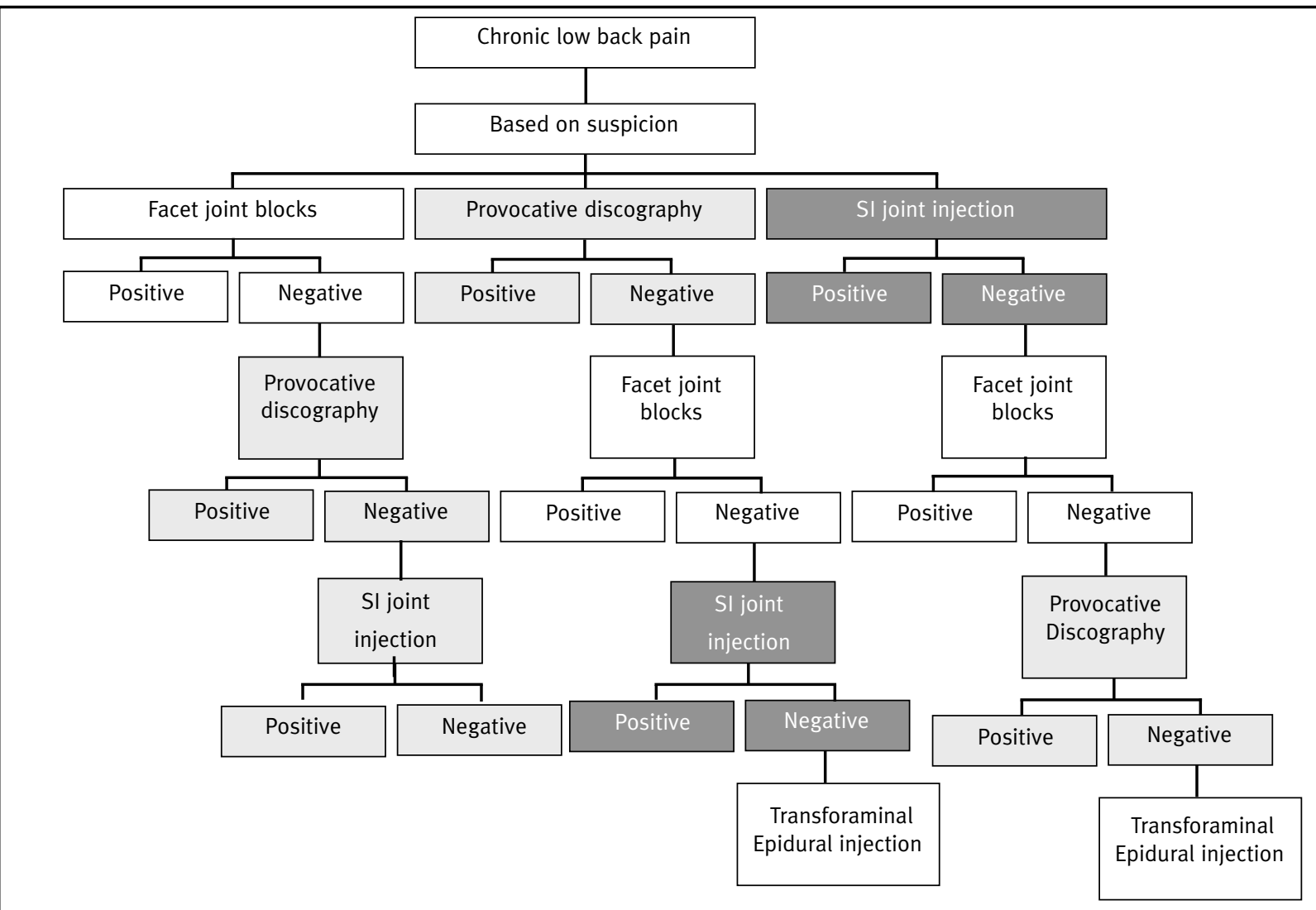

Fig. 3. An algorithmic approach to diagnosis of chronic low back pain without disc herniation (somatic or nonradicular pain)

the ACOEM Guidelines for injuries not sive, encyclopedic review of the available covered by the ACOEM Guidelines.

This analysis demonstrates that the ASIPP Guidelines provide a robust, inci- medical literature, performed in close adherence with AHRQ methodology, to determine the strength of evidence sup- porting various interventional pain procedures for the treatment of chronic low back pain. The ASIPP Guidelines conform more closely with accepted crite- 
ria for Guideline development, complying with 23 out of 25 key elements, than do the ACOEM Guidelines, which comply with 12 out of 25 key elements.

The ACOEM Guidelines are limited to the first three months of injury. Any comments made in these ACOEM Guidelines to the efficacy of treatment should be limited to that time period. Because of the absence of coverage of the ACOEM Guidelines after three months and because of the preponderance of evidence and superior developmental methodology presented in the ASIPP Guidelines, after three months of injury the ASIPP Guidelines should supplement the ACOEM Guidelines; the ASIPP Guidelines are presumptively correct during this time period. Accordingly, it does appear that the ACOEM Guidelines do require supplementation by the ASIPP Guidelines for the treatment of low back injuries persisting beyond three months. If situations arise where there is ambiguity as to which Guideline should prevail, the ASIPP Guidelines should be considered presumptively correct because of their superior methodology and the preponderance of evidence which they provide to support their Guidelines.

\section{Author Affiliation \\ Standiford Helm II, MD \\ Medical Director \\ Pacific Coast Pain Management \\ Center \\ 23792 Rockfield Blvd, Suite 101 \\ Lake Forest, CA 92630 \\ PO Box 2549 \\ Mission Viejo CA 92690-0549 \\ (949) 462-0560 \\ E-mail: drhelm@pcpmc.com}

\section{REFERENCES}

1. Alarcon, CA SB 228.

2. Glass L. Occupational Medicine Practice Guidelines: Evaluation and Management of Common Health Problems and Functional Recovery of Workers, Second Edition. OEM Press, Beverly Farms, 2004.

3. Committee to Advise the Public Health Service on Clinical Practice Guidelines, Institute of Medicine. Field MJ, Lohr KN (eds). Clinical Practice Guidelines. Directions of a New Program. National Academy Press; Washington, 1990.

4. Bigos SJ, Boyer OR, Braen GR et al. Acute
Low Back Problems in Adults. Clinical Practice Guideline Number 4. AHCPR Publication No. 95-0642. Agency for Health Care Policy and Research, Public Health Service, US Department of Health and Human Services, Rockville, December 1994.

5. Manchikanti L, Staats PS, Singh V et al. Evidence based practice guidelines for interventional techniques in the management of chronic spinal pain. Pain Physician, 2003; 6:3-81.

6. Manchikanti L, Heavner JE, Racz GB et al. Methods for evidence synthesis in interventional pain management. Pain Physician, 2003; 6: 89-111.

7. Shaneyfelt T, Mayo-Smith M, Rothwangl J. Are guidelines following guidelines? The methodological quality of clinical practice guidelines in the peer-reviewed medical literature. JAMA 1999; 281:1900-1905.

8. Manchikanti L, Kloth D, Singh V. The role of guidelines in interventional pain medicine: let us separate apples and oranges. Pain Physician 2001; 4:13-23.

9. Pauza KJ, Howel S, Dreyfuss P et al. A randomized, placebo-controlled trial of intradiscal electrothermal therapy for the treatment of discogenic low back pain. Spine J 2004; 4:27-35.

10. Bigos SH, Bowyer O, Braen G et al. Acute Low Back Problems in Adults, Clinical Practice Guidelines No. 14. Rockville, MD, U.S. Department of Health and Human Services, Public Health Service, Agency for Health Care Policy and Research, AHCPR Pub. No. 95-0642, 1994.

11. Kang JD, Georgescu HI, McIntry-Larkin L et al. Herniated lumber intervertebral disks spontaneously produce matrix metalloproteinases, nitric oxide, interleukin-6, and prostaglandin E2. Spine 1996; 21:271-277.

12. Saal JA, Saal JS. Intradiskal electrotherma treatment for chronic diskogenic low back pain: A prospective outcome study with minimum 1-year follow-up. Spine 2000; 25:2622-2627.

13. Saal JA, Saal JS. Intradiskal electrothermal treatment for chronic diskogenic low back pain: A prospective outcome study with a minimum 2-year follow-up. Spine 2002 ; 27:966-973.

14. Carette S, Leclaire R, Marcoux S et al. Epidural corticosteroid injections for sciatica due to herniated nucleus pulposus. $N$ Engl J Med 1997; 336:1634-1640.

15. Hopwood MB, Abram SE. Factors associated with the failure of lumbar epidural steroids. Reg Anesth 1993; 18:238-243.

16. Bowman SJ, Wedderburn L, Whaley A et al. Outcome assessment after epidural corticosteroid injection for low back pain and sciatica. Spine 1993; 18:1345-1350.

17. Nelemans PJ, de Bie RA, De Vet $\mathrm{HC}$ et al. Injection therapy for subacute and chronic benign low back pain. Cochrane Database Sys Rev 2000;(2):CDoo1824
18. Van Tulder MW, Koes BW, Bouter LM. Conservative treatment of acute and chronic nonspecific low back pain. A systemic review of randomized controlled trials of the most common interventions. Spine 1997; 22: $2128-2156$.

19. Rozenberg S, Dubourg G, Khalifa P et al. Efficacy of epidural steroids and low back pain and sciatica. A critical appraisal by a French Task Force of randomized trials. Critical Analysis Group of the French Society for Rheumatology. Rev Rheum Engl Ed 1999; 66:79-85.

20. Indahl A, Velund L, Reikeraas O. Good prognosis for low back pain when left untampered. A randomized clinical trail. Spine 1995; 20:474-477.

21. Carragee EJ, Paragioudakis SJ, Khurana S 2000 Volvo Award winner in clinical studies: lumber high-intensity zone and discography in subjects without low back problems. Spine. 2000; 25:2987-2992.

22. Carragee EJ, Chen Y, Tanner CM et al. Can discography cause long-term back symptoms in previously asymptomatic subjects? Spine 2000; 25:1803-1808.

23. Carragee EJ, Tanner CM, Khurana $S$ et al. The rates of false-positives lumbar discography in select patients without low back symptoms. Spine 2000; 25:1373-1380; discussion 1381.

24. Carragee EJ, Chen Y, Tanner CM et al. Provocative discography in patients after limited lumbar discectomy: a controlled, randomized study of pain response in symptomatic and asymptomatic subjects. Spine 2000; 25:3065-3071.

25. Lee CK, Vessa P, Lee JK. Chronic disabling low back pain syndrome caused by internal disk arrangements: The results of disc excision and posterior lumbar interbody fusion. Spine 1995; 20:356-361.

26. Dreyfuss P, Halbrook B, Pauza K et al. Efficacy and validity of radiofrequency neurotomy for chronic lumber zygapophyseal joint pain. Spine 2000; 25:1270-1277.

27. Van Kleef M. Barendse GA, Kessels A et al. Randomized trial of radiofrequency lumbar facet denervation for chronic low back pain. Spine 1999; 24:1937-1942.

28. Leclaire R, Fortin L, Lambert R et al. Radiofrequency facet joint denervation in the treatment of low back pain: A placebo-controlled clinical trial to assess efficacy. Spine 2001; 26:1411-1416; discussion 1417.

29. Franklin GM, Haug J, Heyer NJ et al. Outcome of lumbar fusion in Washington State workers' compensation. Spine 1994; 19:1897-1903; discussion 1904.

30. Manchikanti L, Singh V, Kloth D et al. Interventional techniques in the management of chronic pain: Part 2.0. Pain Physician 2001; 4:24-98. 